\title{
Is the Obesity Paradox in Type 2 Diabetes Due to Artefacts of Biases? An Analysis of Pooled Cohort Data from the Heinz Nixdorf Recall Study and the Study of Health in Pomerania
}

This article was published in the following Dove Press journal:

Diabetes, Metabolic Syndrome and Obesity: Targets and Therapy

\author{
Bernd Kowall' \\ Andreas Stang $\mathbb{D}^{1,2}$ \\ Raimund $\mathrm{Erbel}^{3}$ \\ Susanne Moebus ${ }^{4}$ \\ Astrid Petersmann ${ }^{5}$ \\ Antje Steveling ${ }^{6}$ \\ Karl-Heinz Jöckel ${ }^{3}$ \\ Henry Völzke 7,8 \\ 'Center of Clinical Epidemiology, Institute \\ for Medical Informatics, Biometry and \\ Epidemiology, Medical Faculty, University \\ Duisburg-Essen, Essen, Germany; ${ }^{2}$ School of \\ Public Health, Department of Epidemiology, \\ Boston University, Boston, MA 021 I8, USA; \\ ${ }^{3}$ Institute for Medical Informatics, Biometry \\ and Epidemiology, University Clinic Essen, \\ University Duisburg-Essen, Essen, Germany; \\ ${ }^{4}$ Center for Urban Epidemiology, Institute \\ for Medical Informatics, Biometry and \\ Epidemiology, University Clinic Essen, Essen, \\ Germany; ${ }^{5}$ Institute of Clinical Chemistry \\ and Laboratory Medicine, University \\ Medicine Greifswald, Greifswald, Germany; \\ ${ }^{6}$ Department of Internal Medicine, \\ University Medicine Greifswald, Greifswald, \\ Germany; ${ }^{7}$ Department of Study of Health \\ in Pomerania/Clinical-Epidemiological \\ Research, Institute for Community \\ Medicine, University Medicine Greifswald, \\ Greifswald, Germany; ${ }^{8}$ German Center for \\ Diabetes Research, Site Greifswald, \\ Greifswald, Germany
}

Correspondence: Bernd Kowall Center of Clinical Epidemiology, c/o Institute of Medical Informatics, Biometry and Epidemiology (IMIBE), Hufelandstraße 55, Essen 45147, Germany

Tel +49-20l-92239-295

Fax +49-201-92239-333

Email bernd.kowall@uk-essen.de

\begin{abstract}
Aims/Hypothesis: There is controversy on whether an obesity paradox exists in type 2 diabetes, ie, that mortality is lowest in overweight or obesity. We examined the role of potential biases in the obesity paradox.

Methods: From two regional population-based German cohort studies - the Heinz Nixdorf Recall Study and the Study of Health in Pomerania (baseline examinations 2000-2003/19972001 ) - 1187 persons with diabetes at baseline were included (mean age 62.6 years, $60.9 \%$ males). Diabetes was ascertained by self-report of physician's diagnosis, antidiabetic medication, fasting/random glucose or haemoglobin A1c. Mortality data were assessed for up to 17.7 years. We used restricted cubic splines and Cox regression models to assess associations between body mass index (BMI) and mortality. Sensitivity analyses addressed, inter alia, exclusion of early death cases, of persons with cancer, kidney disease or with history of cardiovascular diseases, and of ever smokers. Furthermore, we examined the role of treatment bias and collider bias for the obesity paradox.
\end{abstract}

Results: In spline models, mortality risk was lowest for BMI at about $31 \mathrm{~kg} / \mathrm{m}^{2}$. Sensitivity analyses carried out one after another had hardly any impact on this result. In our cohort, persons with diabetes and BMI $\geq 30 \mathrm{~kg} / \mathrm{m}^{2}$ did not have better treatment than non-obese patients, and we found that collider bias played only a minor role in the obesity paradox.

Conclusion: In a cohort of 1187 persons with diabetes, mortality risk was lowest in persons with moderate obesity. We cannot explain this result by a variety of sensitivity analyses.

Keywords: collider bias, diabetes, mortality, obesity paradox, overweight

\section{Introduction}

There is still controversy on the obesity paradox, which means that mortality is lowest in overweight or obese persons. In a meta-analysis of 97 prospective studies with 2.9 million participants, Flegal et al found that in the general population all-cause mortality was lowest in overweight and class I obesity $(\mathrm{HR}=0.94,95 \% \mathrm{CI}$ : $0.91-0.96$; and $\mathrm{HR}=0.95,95 \% \mathrm{CI}: 0.88-1.01$, compared to normal weight), whereas mortality was increased in obesity class II and III (HR=1.29, 95\% CI: $1.18-1.41) .{ }^{1}$ However, other authors claimed that the obesity paradox was due to methodical limitations like residual confounding due to smoking. ${ }^{2,3}$ In a meta-analysis of 239 prospective studies with individual data of almost four million never-smokers without chronic diseases at recruitment, all-cause mortality was lowest in 20.0 to $25.0 \mathrm{~kg} / \mathrm{m}^{2}$. 
The same controversy has come up on the question whether there is an obesity paradox in persons with diabetes. ${ }^{4}$ In recent large meta-analyses on persons with diabetes, U-shaped associations between body mass index (BMI) and all-cause mortality were reported with nadirs in the range of overweight or mild obesity. ${ }^{5-7}$ From 24 cohort studies, Zaccardi et al found that the optimal BMI $\left(\mathrm{kg} / \mathrm{m}^{2}\right)$ was 31-35 in men, and 28-31 in women, and from 16 cohort studies, Chang et al observed that hazard ratios were lowest for overweight and class I obesity (HR $=0.86$ (95\% CI: 0.78 to 0.96 ), and HR $=0.88$ (95\% CI: 0.78 to 1.00), respectively, compared to BMI $18.5-24.9){ }^{5,6} \mathrm{In}$ a recent study using data of the UK Biobank, the obesity paradox was reported to be even stronger in persons with than in persons without diabetes. ${ }^{8}$ In the Korean KOMERIT study, the optimal BMI depended on the state of glycemia, and the poorer the state of glycemia was, the larger the optimal BMI $\left(\mathrm{kg} / \mathrm{m}^{2}\right)$ was (23.5-27.9 in normoglycemia, 25-27.9 in impaired fasting glucose, 26.5-29.4 in prevalent diabetes). ${ }^{9}$

In many studies on patients with diabetes, a U-shaped associations between BMI and mortality was found, and mortality was lowest for overweight or obesity. ${ }^{10-15}$ In other studies, different results were found: inverse associations (mortality decreases with increasing BMI), ${ }^{16-18}$ or a linear increase (mortality increases with rising BMI). ${ }^{19}$ In a study of incident diabetes, Tobias et al reported a U-shaped association with the lowest mortality for $22.5-24.9 \mathrm{~kg} / \mathrm{m}^{2,20}$ and in a subsequent paper, Tobias and Manson stated that

the obesity paradox is likely an artefact of biases, and once these are accounted for, it is evident that compared with normal body weight, excess body weight is associated with a greater mortality risk. ${ }^{21}$

Other authors assume that BMI is not an appropriate anthropometric measure to assess whether the obesity paradox is real. ${ }^{22,23}$

This brought us to estimate hazard ratios for the association between BMI and waist circumference (WC), respectively, and all-cause mortality, and to rigorously carry out several sensitivity analyses accounting for potential biases as suggested by Tobias et al and Standl et al. ${ }^{21,24}$ These biases refer to coexisting comorbidities and early death from comorbidities, overadjustment for mediators like hypertension, lack of adjustment for diabetes duration, unintentional weight loss, residual confounding due to smoking, and better treatment of diabetes patients with obesity. Moreover, some epidemiologists state that the obesity paradox can be explained away by collider bias, which results from conditioning on prevalent diabetes. ${ }^{16,25}$ Our aim is to use data from two German cohort studies (the population based Heinz-Nixdorf Recall (HNR) Study and the population based Study of Health in Pomerania (SHIP)) to address the aforementioned potential biases.

\section{Methods \\ Study Population}

The prospective population-based HNR cohort study was carried out in three large German cities (Mülheim, Essen, Bochum) in the Ruhr district. Details of the aims and the design of the study have been published earlier. ${ }^{26}$ Participants were invited to the study center for the first time between 2000 and 2003 (T0), and 4814 persons in the age range between 45 to 75 years $(49.8 \%$ males) participated in the baseline examinations. The next visits to the study center took place between 2005 and 2008 (T1), and between 2011 and 2015 (T2), respectively. The median time between $\mathrm{T} 0$ and $\mathrm{T} 1$ was 5.1 years, and 5.2 years between $\mathrm{T} 1$ and $\mathrm{T} 2$. During the examinations in the study center, participants filled in questionnaires, took part in face-to-face interviews and underwent physical examinations including extensive laboratory tests. Seven hundred and thirty-three persons with diabetes at baseline were included in the present study (cf. flow-chart, Figure 1).

SHIP is a population-based cohort study sampled in West Pomerania, a rural area in the Northeast of Germany. Details of the aims and design of SHIP have been described earlier. ${ }^{27,28}$ Baseline visits to the study center took place between 1997 and 2001 (SHIP-0). 4308 subjects (69\% of all eligible persons) took part in the baseline examinations. After 5,11 and 17 years participants were invited again to the study center for further examinations (SHIP-1, SHIP-2, SHIP-3). Examinations included medical and oral health examinations, computer-assisted interviews and self-administered questionnaires. Four hundred and fifty-four persons with diabetes at baseline were included in the present study (cf. flow-chart, Figure 1). 26 persons $(5.7 \%)$ were younger than 45 years.

Both studies were approved by the responsive ethics committees at the Medical Faculties of the University Clinic Essen and of the University of Greifswald, respectively. All participants in the studies provided written informed consent. 


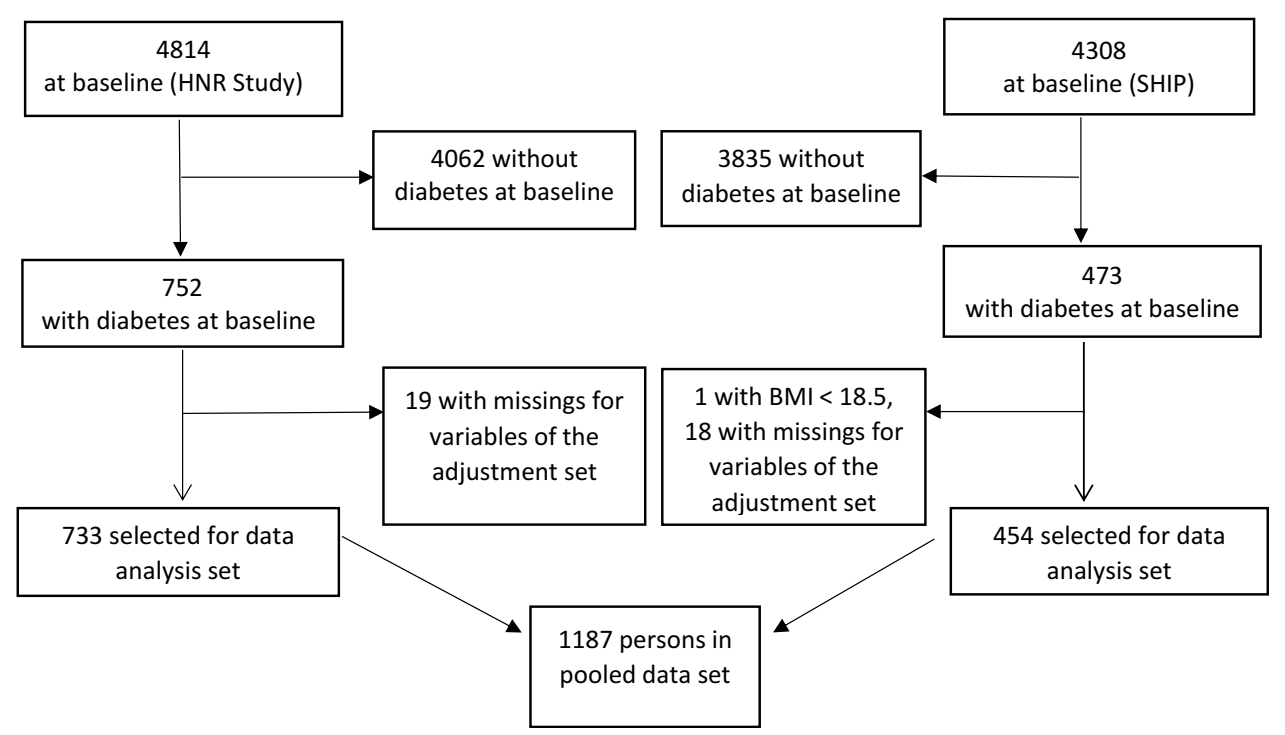

Figure I Flow-chart of persons entering the data analysis set.

The pooled data for the present analyses included 1187 persons with diabetes and with BMI $>18.5 \mathrm{~kg} / \mathrm{m}^{2}$. Persons with type-1 diabetes were still included, but excluded in later sensitivity analyses.

\section{Assessment of Diabetes}

In both cohorts, participants were diagnosed with diabetes if one of the following conditions were fulfilled: (1) participants reported that a physician had told them that they had diabetes; (2) participants took antidiabetic drugs (Anatomical Therapeutic Chemical (ATC) Code A10); (3) participants had an overnight fast of $\geq 8$ hours and a glucose concentration of $>125 \mathrm{mg} / \mathrm{dl}$, or participants without an overnight fast had a glucose concentration $\geq 200 \mathrm{mg} / \mathrm{dl}$; (4) haemoglobin (Hb)Alc was $\geq 6.5 \%$. Diabetes was considered as previously known if condition (1) or (2) was fulfilled.

\section{Assessment of Anthropometric Measures}

For the HNR Study and for SHIP, details of the measurement of weight and waist circumference have been given elsewhere. ${ }^{29,30} \mathrm{BMI}$ was calculated as (weight $[\mathrm{kg}]$ )/(height $[\mathrm{m}]^{2}$ ). Fat-free mass (FFM) was estimated using a formula by Kuch et al which had been validated in SHIP: FFM=5.1 $\mathrm{x}$ (height $[\mathrm{m}]^{1.14}$ ) $\mathrm{x}$ (weight $[\mathrm{kg}]^{0.41}$ ) for men, $\mathrm{FFM}=5.34$ $\mathrm{x}$ (height $[\mathrm{m}]^{1.47}$ ) $\mathrm{x}$ (weight $[\mathrm{kg}]^{0.33}$ ) for women. ${ }^{31,32}$ Fat mass $(\mathrm{kg})$ was calculated as body weighted minus FFM.

\section{Assessment of Vital Status}

In the HNR study, all death certificates of the participating cities were checked regularly. For the present study, mortality data were assessed until September 30, 2018. Person time was calculated for all study participants from the date of the first visit to the study centre. In SHIP, mortality data were collected annually from population registries.

For assessment of covariates and development of the diabetes genetic risk score in the HNR Study cf. Supplementary Material.

\section{Statistical Analyses}

Baseline characteristics (proportions (\%), means (standard deviations (SD))) were calculated separately for the two cohorts and for categories of BMI.

We used Cox proportional hazards models to estimate hazard ratios (HR) with 95\% confidence intervals (CI) for mortality across categories of BMI. We added interaction terms of the exposure variable and survival time to the model to check whether the proportional hazards assumption was met (alpha level $=0.1$ ). In the main analyses, we adjusted for age, sex, educational years (total years of formal education and vocational training), living together with a partner, physical activity, smoking, hypertension, history of myocardial infarction or stroke at baseline, cancer not in full remission at baseline, and study center. The following categories of BMI $\left(\mathrm{kg} / \mathrm{m}^{2}\right)$ were used as exposure variables: $18.5-<25.0$, $25.0-<30.0,30.0-<35.0, \geq 35.0$. Associations between BMI and mortality were also assessed using restricted cubic splines, with 3 knots defined at the 10th, the 50th, and the 90th percentile of BMI.

Starting from the main analyses, the following sensitivity analyses were done: Sensitivity analysis 1: exclusion of 
persons with diagnosis of diabetes before the age of 30. Sensitivity analysis 2: adjustment for diabetes duration. Sensitivity analysis 3: no adjustment for hypertension. Sensitivity analysis 4: exclusion of death cases during the first two years of follow-up. Sensitivity analysis 5: exclusion of participants with cancer not in full remission/history of stroke or myocardial infarction/chronic kidney disease. Participants with heart failure were only excluded for participants of the Recall Study, because heart failure was not assessed in SHIP. Sensitivity analysis 6: exclusion of ever smokers.

To look for treatment bias, characteristics of diabetes treatment (age at diagnosis, diabetes duration, diabetes therapy, HbA1c, lipids) in persons with previously known diabetes were assessed separately for categories of BMI ( $\geq 30$ versus $<30 ; \geq 27.5$ versus $<27.5$ ).

To look for collider bias, we calculated proportions (\%) and means $( \pm \mathrm{SD})$, respectively, of risk factors for type 2 diabetes by BMI category $(<27.5$ versus $\geq 27.5$ ) separately for the whole HNR population and for persons with type 2 diabetes in the HNR Study. Fitting a log-linear model with a Poisson working likelihood and robust standard errors, we estimated prevalence ratios with $95 \%$ confidence intervals to compare the prevalence of a given diabetes risk factor in persons with lower BMI $(<27.5)$ to the prevalence of this risk factor in persons with higher BMI $(\geq 27.5)$.

Four additional analyses were done:

With HNR data, the date of T1 was used as baseline, and BMI measured about 5 years earlier at T0 was used as the exposure variable. Fat-free mass was added to the models mentioned above to assess whether this potentially mediating variable has an impact on the strength of the BMI mortality association. We used WC $(\mathrm{cm})$ instead of BMI as exposure variable with the following categories proposed by Leitzmann et al: ${ }^{33}<94,94-<102,102-<118, \geq 118$ for men, $<80,80-<88,88-<96, \geq 96$ for women. These categories include cut-points of 80 and $88 \mathrm{~cm}$ for women, and 94 and $102 \mathrm{~cm}$ for men, respectively, used by the WHO to define increased and substantially increased obesity. ${ }^{34}$ Furthermore, we additionally adjusted for $\mathrm{WC}$ in the main analysis.

All statistical analyses were performed using SAS version 9.4 .

\section{Results}

In the pooled cohorts of diabetes patients, $45.5 \%$ of the participants were obese, $41.4 \%$ were overweight, and
$13.1 \%$ had normal weight. The prevalence of previously known diabetes was around $60 \%$ in all four BMI categories, and with $56 \mathrm{mmol} / \mathrm{mol}(7.3 \%)$, HbAlc was highest in BMI $\geq 35 \mathrm{~kg} / \mathrm{m}^{2}$ (Table 1). Furthermore, in BMI $\geq$ $35 \mathrm{~kg} / \mathrm{m}^{2}$, the prevalence of hypertension was higher, and the lipid concentrations were less favourable than in patients with lower BMI. In SHIP, diabetes control was poorer than in the HNR cohort (HbAlc $55 \mathrm{mmol} / \mathrm{mol}$ $(7.2 \%)$ versus $50 \mathrm{mmol} / \mathrm{mol}(6.7 \%))$, SHIP participants had higher values of blood pressure and, moreover, SHIP participants had three years of education less than HNR participants (Supplementary Table 1). In the pooled data set, person times ranged from 0.05 to 17.75 years.

With covariable adjustment of the main analysis, the restricted cubic spline regression shows a U-shaped association between BMI and mortality with the lowest mortality risk at around $30-32 \mathrm{~kg} / \mathrm{m}^{2}$ (Figure $2 \mathrm{~A}$ ). When the sensitivity analyses 1-5 were done, the shape of the curve hardly changed (Figure 2B).

In the main analysis with all participants of both cohorts combined, all-cause mortality was highest for BMI $<25$ $(\mathrm{HR}=1.22(95 \% \mathrm{CI}: 0.90-1.66))$ and $\mathrm{BMI} \geq 35(\mathrm{HR}=1.22$ (0.91-1.63)), and lowest for the reference category (BMI 30 $-<35$ ) (Table 2). The sensitivity analyses $1-5$ hardly changed this pattern. Confining the analysis to never smokers, the mortality risk for $\mathrm{BMI} \geq 35$ increased $(\mathrm{HR}=1.89$ (1.08-3.32)). Additional adjustment for fat-free mass had little impact on the hazard ratios $(\mathrm{eg}, \mathrm{HR}=1.10(0.79-1.54)$ for $\mathrm{BMI}<25$, $\mathrm{HR}=0.99(0.78-1.26)$ for BMI $25-<30$, and $\mathrm{HR}=1.28(0.95-$ 1.73 ) for $\mathrm{BMI} \geq 35$ in the main analysis). Likewise, additional adjustment for waist circumference had only little influence on the hazard ratios $(\mathrm{eg}, \mathrm{HR}=1.30(0.86-1.95)$ for $\mathrm{BMI}<25$, $\mathrm{HR}=1.07(0.82-1.40)$ for BMI $25-<30$, and $\mathrm{HR}=1.17(0.84-$ 1.63) for $\mathrm{BMI} \geq 35$ in the main analysis).

When the main analysis was done separately for 710 (59.8\%) persons with previously known and 477 (40.2\%) persons with newly detected diabetes, results were unchanged. For previously known diabetes, the adjusted hazard ratios were 1.27 (95\% CI: 0.88-1.83), 0.94 (0.71-1.25), 1 (reference), and $1.09(0.76-1.56)$ for BMI $18.5-<25$, 25- $<30$, $30-<35$, and $\geq 35$, respectively. For persons with newly detected diabetes, the corresponding HRs were $1.16(0.65-$ 2.05), 1.17 (0.78-1.76), 1 (reference), and 1.41 (0.84-2.35).

The U-shaped pattern was even more pronounced when the analyses were replicated with participants from the HNR study who had diabetes at T1: HR was 1.92 (1.17-3.14) for BMI $<25$, and HR was 1.65 (1.07-2.55) for $\mathrm{BMI} \geq 35$ (Table 3 ). When this analysis was repeated 
Table I Baseline Characteristics of Participants with Diabetes Mellitus by Category of BMI: Pooled Data of the Heinz Nixdorf Recall Study and SHIP

\begin{tabular}{|c|c|c|c|c|c|}
\hline & & BMI $\geq 18.5,<25 \mathrm{~kg} / \mathrm{m}^{2}$ & $B M I \geq 25,<30 \mathrm{~kg} / \mathrm{m}^{2}$ & BMI $\geq 30,<35 \mathrm{~kg} / \mathrm{m}^{2}$ & BMI $\geq 35 \mathrm{~kg} / \mathrm{m}^{2}$ \\
\hline \multicolumn{2}{|l|}{$\mathrm{N}$} & 155 & 492 & 347 & 193 \\
\hline \multicolumn{2}{|l|}{ Age (years) } & $62.8 \pm 11.4$ & $63.2 \pm 9.2$ & $62.2 \pm 8.6$ & $61.5 \pm 8.5$ \\
\hline \multicolumn{2}{|c|}{ Sex (males (\%)) } & 47.7 & 70.5 & 61.1 & 46.6 \\
\hline \multicolumn{2}{|c|}{ Years of education (ISCED) } & $12.8 \pm 3.3$ & $12.7 \pm 2.9$ & $12.6 \pm 3.2$ & $12.0 \pm 3.2$ \\
\hline \multicolumn{2}{|c|}{ Living with a partner (\%) } & 70.3 & 80.9 & 74.9 & 72.5 \\
\hline \multicolumn{2}{|c|}{ BMI $\left(\mathrm{kg} / \mathrm{m}^{2}\right)$} & $23.2 \pm 1.4$ & $27.7 \pm 1.4$ & $32.2 \pm 1.5$ & $38.9 \pm 3.9$ \\
\hline \multicolumn{2}{|c|}{$\mathrm{HbAlc}(\mathrm{mmol} / \mathrm{mol})$} & $51 \pm 16$ & $51 \pm 15$ & $52 \pm 14$ & $56 \pm 17$ \\
\hline \multicolumn{2}{|l|}{$\mathrm{HbAlc}(\%)$} & $6.8 \pm 1.5$ & $6.8 \pm 1.4$ & $6.9 \pm 1.3$ & $7.3 \pm 1.6$ \\
\hline \multicolumn{2}{|c|}{ Diabetes duration (years) } & $7.6 \pm 10.4$ & $5.9 \pm 8.7$ & $5.4 \pm 8.6$ & $5.3 \pm 8.4$ \\
\hline \multicolumn{2}{|c|}{ Known diabetes $(\%)$} & 61.3 & 60.6 & 56.8 & 62.2 \\
\hline \multicolumn{2}{|c|}{ Systolic blood pressure $(\mathrm{mm} \mathrm{Hg})$} & $138.4 \pm 23.7$ & $146.1 \pm 21.2$ & $144.7 \pm 21.4$ & $143.6 \pm 22.0$ \\
\hline \multicolumn{2}{|c|}{ Diastolic blood pressure $(\mathrm{mm} \mathrm{Hg})$} & $79.0 \pm 9.7$ & $83.9 \pm 12.0$ & $84.2 \pm 11.7$ & $83.6 \pm 11.1$ \\
\hline \multicolumn{2}{|c|}{ Hypertension (\%) } & 60.7 & 79.9 & 85.6 & 90.7 \\
\hline \multicolumn{2}{|c|}{ LDL cholesterol (mg/dl) } & $137.5 \pm 39.0$ & $139.9 \pm 41.0$ & $139.9 \pm 37.4$ & $145.4 \pm 39.6$ \\
\hline \multicolumn{2}{|c|}{ HDL cholesterol (mg/dl) } & $58.2 \pm 18.6$ & $49.7 \pm 15.0$ & $48.2 \pm 14.0$ & $46.4 \pm 12.2$ \\
\hline \multicolumn{2}{|c|}{ Triglycerides (mg/dl) } & $128(89 ; 189)$ & $163(111 ; 243)$ & $177(125 ; 243)$ & $186(142 ; 261)$ \\
\hline \multirow[t]{3}{*}{ Smoking (\%) } & Current & 28.4 & 20.9 & 17.9 & 15.5 \\
\hline & Former & 27.1 & 46.8 & 47.0 & 37.3 \\
\hline & Never & 44.5 & 32.3 & 35.2 & 47.2 \\
\hline \multicolumn{2}{|c|}{ Physically active (yes) (\%) } & 25.8 & 25.6 & 23.3 & 23.3 \\
\hline \multicolumn{2}{|c|}{ Estimated fat mass (\% } & $26.6 \pm 5.3$ & $32.4 \pm 5.0$ & $39.1 \pm 4.9$ & $46.4 \pm 12.2$ \\
\hline \multicolumn{2}{|c|}{ Cancer $(\%)^{\mathrm{a}}$} & 0 & 1.0 & 0.6 & 1.0 \\
\hline \multicolumn{2}{|c|}{ History of stroke (\%) } & 5.8 & 4.7 & 4.9 & 3.6 \\
\hline \multicolumn{2}{|c|}{ History of myocardial infarction (\%) } & 5.8 & 6.1 & 11.2 & 10.4 \\
\hline \multicolumn{2}{|c|}{ Follow-up time (years) } & $12.3 \pm 4.8^{\mathrm{b}}$ & $12.6 \pm 4.5^{c}$ & $12.9 \pm 4.4^{\mathrm{d}}$ & $13.1 \pm 3.7^{\mathrm{e}}$ \\
\hline
\end{tabular}

Notes: Values are expressed as mean \pm standard deviation, median (first quartile, third quartile), or proportion (\%). ${ }^{a}$ Under treatment in the last 12 months (SHIP) OR cancer not in full remission (HNR Study). ${ }^{\mathrm{b}}$ Range 0.1-17.7; ${ }^{\mathrm{C}}$ Range 0.2-17.7; ${ }^{\mathrm{d}}$ Range 0.4-17.7; ${ }^{\mathrm{e}}$ Range 1.6-17.7.

Abbreviation: ISCED, International Standard Classification of Education.

with BMI measured at T0 instead of BMI measured at T1, the U-shaped association persisted $(\mathrm{HR}=1.65(0.96-2.84)$ for $\mathrm{BMI}<25$, and $\mathrm{HR}=2.10(1.35-3.28)$ for $\mathrm{BMI} \geq 35)$. After carrying out the first five sensitivity analyses with BMI measured at $\mathrm{T} 0$ and participants with diabetes at $\mathrm{T} 1$, the results hardly changed; for BMI $\geq 35$, the mortality risk was even stronger $(\mathrm{HR}=2.39$ (1.39-4.12)).

Obese persons $\left(\mathrm{BMI} \geq 30 \mathrm{~kg} / \mathrm{m}^{2}\right.$ ) with previously known diabetes did not differ from non-obese persons (BMI $<30 \mathrm{~kg} / \mathrm{m}^{2}$ ) with regard to age at diagnosis of diabetes (53.1 versus 53.7 years) (Supplementary Table 2). In addition, the proportion of participants with previously known diabetes was about the same in both BMI categories (58.7 versus $60.7 \%$ ); the same is true for the proportion of persons receiving diabetes therapy with pills and/or insulin (81.4 versus $82.9 \%$ ). However, diabetes control as measured by $\mathrm{HbAlc}$ was worse in obese persons ( 7.3 versus $7.0 \%)$.
Results were similar when $27.5 \mathrm{~kg} / \mathrm{m}^{2}$ was used as BMI cut-off.

From prevalences of diabetes risk factors in $\mathrm{BMI}<27.5 \mathrm{~kg} /$ $\mathrm{m}^{2}$ and in $\mathrm{BMI} \geq 27.5 \mathrm{~kg} / \mathrm{m}^{2}$, prevalence ratios were calculated with $\mathrm{BMI} \geq 27.5 \mathrm{~kg} / \mathrm{m}^{2}$ as reference category. For all risk factors of diabetes, these prevalence ratios were larger in persons with diabetes than in the whole study population (Table 4). In persons with diabetes, the number of diabetes risk alleles was slightly larger in BMI $<27.5 \mathrm{~kg} / \mathrm{m}^{2}$ as compared with BMI $\geq 27.5 \mathrm{~kg} / \mathrm{m}^{2}$ (difference in number of risk alleles $=1.0,95 \%$ CI: 0.1 to 2.0 ). In the whole study group, the corresponding difference was 0.3 ( $95 \% \mathrm{CI}$ : -0.1 to 0.6 ).

With WC as anthropometric measure instead of BMI, an increased mortality was observed in none of the three higher WC categories $(\geq 94 \mathrm{~cm}$ in men, $\geq 80 \mathrm{~cm}$ in women) in the main and in the sensitivity analyses 1-5 (Supplementary Table 3). 

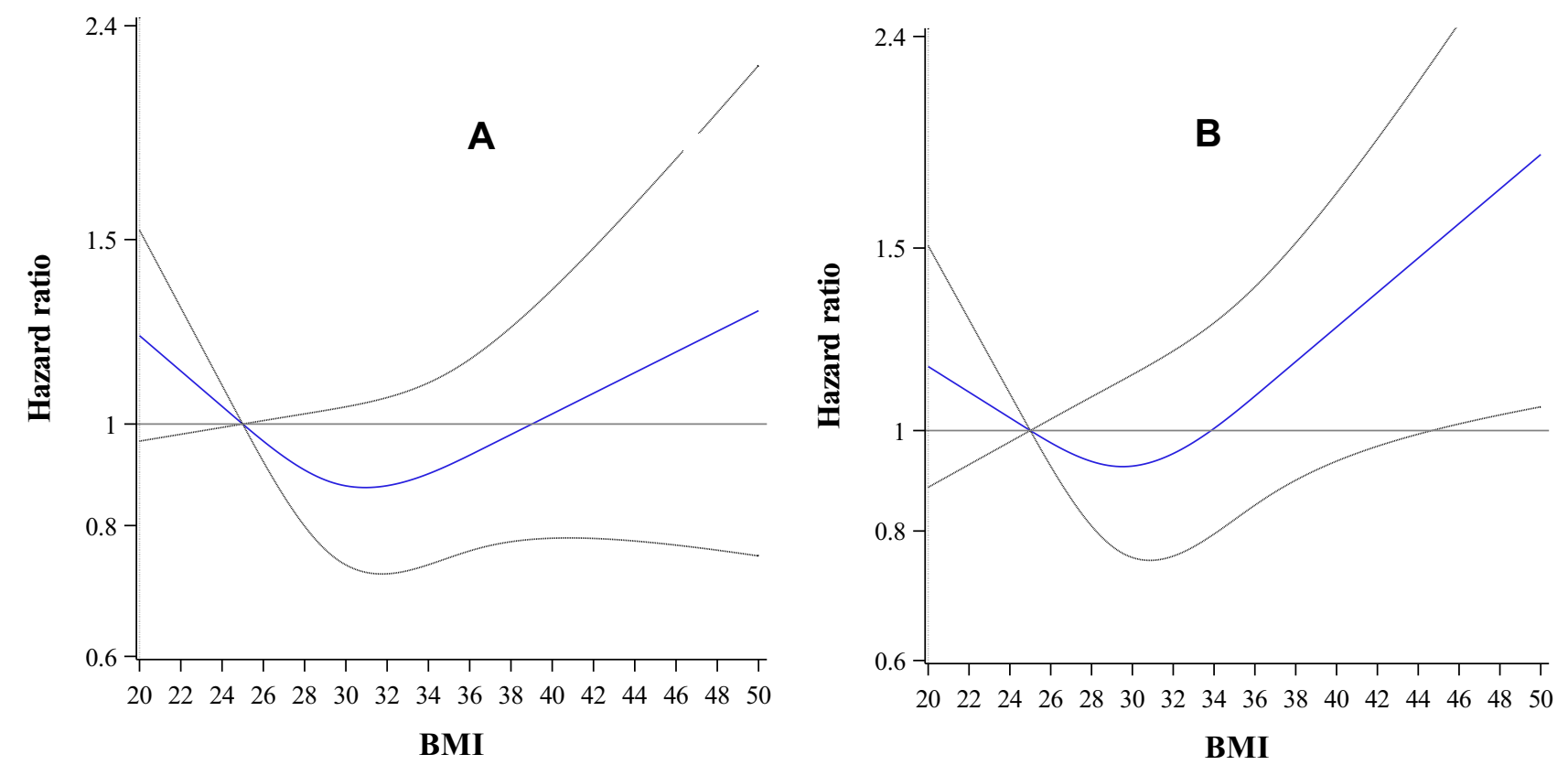

Figure 2 Hazard ratios $(95 \% \mathrm{Cl})$ for all-cause mortality associated with BMI in persons with diabetes at baseline: Pooled data of the Heinz Nixdorf Recall Study and SHIP. (A) Main analysis with adjustment for age, sex, educational years, living together with a partner, physical activity, hypertension, smoking (never, ever, current), cardiovascular disease (coronary heart disease, stroke) at baseline, cancer at baseline, study center ( $\mathrm{N}=\mathrm{I}$ I87). (B) Hazards ratios after sensitivity analyses I-5 (cf. methods section).

\section{Discussion}

In our main analyses of participants with diabetes, we confirmed the U-shaped association between BMI and mortality with lowest mortality at moderate obesity. We did several sensitivity analyses to address potential biases which were discussed by some authors as potential reasons why no excess mortality was observed in overweight or obese persons with diabetes. All these sensitivity analyses led to virtually unchanged results.

\section{The Role of Reverse Causation, Smoking and Overadjustment}

Reverse causation bias is one of the main arguments brought forward against the obesity paradox. ${ }^{21,24}$ Prevalent major comorbidity at baseline may lead to unintentional weight loss, and thus be a confounding condition for the association between BMI and all-cause mortality. We addressed this potential bias in three ways. Excluding persons with history of myocardial infarction or stroke or with cancer not in full remission or with kidney diseases, and additional exclusion of death cases during the first two years of follow-up had hardly any impact on the effect estimates of mortality rate. In an additional analysis, we used BMI measured about five years prior to the date from which person-time was calculated, but again results hardly differed from the main analyses.
Smoking is a strong confounder of the association between BMI and mortality, and residual confounding may be a strong reason for the occurrence of bias. Therefore, adjusting for smoking and restricting the analyses to non-smokers may not lead to equivalent results. Using data of the US Biobank, Jenkins et al observed an obesity paradox in participants with type 2 diabetes. ${ }^{35}$ This U-shaped relationship with lowest mortality in class I obesity was modified by smoking status: It was strongest in current smokers, and less pronounced, but still present in never smokers. In the present study, the mortality risk increased in the strongly obese $(\mathrm{HR}=1.89,95 \% \mathrm{CI}$ : 1.08 to 3.32 for $\mathrm{BMI} \geq 35$ versus $\mathrm{BMI} 30-<35$ ) after exclusion of ever smokers but this result needs confirmation in a larger subpopulation of never-smokers.

Tobias and Manson suggested that inappropriate adjustment for potential mediators like hypertension, cholesterol levels and severity of diabetes may to lead to underestimates of mortality in the obese. ${ }^{21}$ Our final models included none of these potential mediators but still results remained virtually the same.

\section{Appropriateness of BMI as Measure of Obesity}

BMI poorly reflects fat mass and fat distribution whereas waist circumference mirrors the amount of abdominal fat. $^{22,23}$ In 5435 participants of the EPIC study with 
Table 2 Hazard Ratios of All-Cause Mortality by BMI Category in Persons with Diabetes at Baseline: Pooled Data of the Heinz Nixdorf Recall Study and SHIP

\begin{tabular}{|c|c|c|c|c|c|c|}
\hline & $\mathbf{N}$ & Deaths & Person Years & $\begin{array}{l}\text { Mortality Rate } \\
\text { (per } 1000 \text { py) }\end{array}$ & HR Crude $(95 \% \mathrm{Cl})$ & HR Adjusted $(95 \% \mathrm{Cl})$ \\
\hline \multicolumn{7}{|l|}{ All (N=I I 87) } \\
\hline BMI I8.5-<25 & 155 & 67 (43.3\%) & 1912 & 35.0 & $1.32(0.98-1.78)$ & $1.22^{\mathrm{a}}(0.90-1.66)$ \\
\hline BMI $25-<30$ & 492 & $190(38.6 \%)$ & 6197 & 30.7 & $1.15(0.91-1.44)$ & $1.04^{\mathrm{a}}(0.82-1.31)$ \\
\hline BMI $30-<35$ & 347 & $120(34.6 \%)$ & 4484 & 26.8 & I & I \\
\hline $\mathrm{BMI} \geq 35$ & 193 & 74 (38.3\%) & 2537 & 29.2 & $1.09(0.8 \mathrm{I}-1.45)$ & $1.22^{\mathrm{a}}(0.91-1.63)$ \\
\hline \multicolumn{7}{|c|}{ In addition: Exclusion of diagnosis of diabetes before the age of $30(\mathrm{~N}=|| 157)$} \\
\hline BMI I8.5-< 25 & 146 & $63(43.2 \%)$ & 1806 & 34.9 & $1.30(0.95-1.76)$ & $1.18(0.86-1.61)$ \\
\hline BMI $25-<30$ & 481 & $188(39.1 \%)$ & 6045 & 31.1 & $1.15(0.92-1.45)$ & $1.04(0.82-1.31)$ \\
\hline BMI $30-<35$ & 341 & $119(34.9 \%)$ & 4394 & 27.1 & 1 & I \\
\hline $\mathrm{BMI} \geq 35$ & 189 & $73(38.6 \%)$ & 2481 & 29.4 & $1.08(0.81-1.45)$ & $1.22(0.91-1.63)$ \\
\hline \multicolumn{7}{|c|}{ In addition: Adjustment for diabetes duration $(\mathrm{N}=1$ | 43$)$} \\
\hline BMI I8.5-< 25 & 145 & 63 & |79| & 35.2 & $1.32(0.97-1.80)$ & $1.16(0.84-1.59)$ \\
\hline BMI $25-<30$ & 477 & 187 & 5993 & 31.2 & $1.17(0.93-1.48)$ & $1.03(0.8 \mathrm{I}-1.30)$ \\
\hline BMI $30-<35$ & 334 & 115 & 4304 & 26.7 & 1 & 1 \\
\hline $\mathrm{BMI} \geq 35$ & 187 & 73 & 2450 & 29.8 & I.II (0.83-I.49) & $1.24(0.92-1.67)$ \\
\hline \multicolumn{7}{|c|}{ In addition: No adjustment for hypertension $(\mathrm{N}=\mathrm{I}$ | 43) } \\
\hline BMI $18.5-<25$ & 145 & 63 & $|79|$ & 35.2 & $1.32(0.97-1.80)$ & I.I $4(0.83-1.56)$ \\
\hline BMI $25-<30$ & 477 & 187 & 5993 & 31.2 & $1.17(0.93-1.48)$ & $1.02(0.8 \mathrm{I}-1.30)$ \\
\hline BMI $30-<35$ & 334 & 115 & 4304 & 26.7 & 1 & I \\
\hline $\mathrm{BMI} \geq 35$ & 187 & 73 & 2450 & 29.8 & I.II (0.83-I.49) & $1.26(0.94-1.70)$ \\
\hline \multicolumn{7}{|c|}{ In addition: Exclusion of death cases during the first two years of follow-up $(\mathbf{N}=|||| 2)$} \\
\hline BMI $18.5-<25$ & 138 & $56(40.6 \%)$ & 1785 & 31.4 & $1.27(0.92-1.75)$ & $1.08(0.78-1.50)$ \\
\hline BMI $25-<30$ & 462 & $172(37.2 \%)$ & 5879 & 28.8 & $1.16(0.91-1.48)$ & I.0I $(0.79-1.30)$ \\
\hline BMI $30-<35$ & 326 & $107(32.8 \%)$ & 4294 & 24.9 & 1 & I \\
\hline $\mathrm{BMI} \geq 35$ & 186 & $72(38.7 \%)$ & 2448 & 29.4 & $1.18(0.87-1.59)$ & $1.34(0.99-1.80)$ \\
\hline \multicolumn{7}{|c|}{ In addition: Exclusion of participants with known cancer/CVD/kidney disease ( $N=867)$} \\
\hline BMI $18.5-<25$ & 114 & $42(36.8 \%)$ & 1527 & 27.5 & I.27 (0.87-I.87) & $1.04(0.70-1.54)$ \\
\hline BMI $25-<30$ & 371 & $125(33.7 \%)$ & 4882 & 25.6 & $1.19(0.89-1.59)$ & $1.01(0.75-1.36)$ \\
\hline BMI $30-<35$ & 242 & $70(28.9 \%)$ & 3233 & 21.7 & I & 1 \\
\hline $\mathrm{BMI} \geq 35$ & 140 & $52(37.1 \%)$ & 1858 & 28.0 & $1.29(0.90-1.85)$ & $1.51(1.05-2.16)$ \\
\hline \multicolumn{7}{|c|}{ In addition: Exclusion of ever smokers $(\mathbf{N}=\mathbf{3 3 3})$} \\
\hline BMI $18.5-<25$ & 53 & $19(35.9 \%)$ & 685 & 27.7 & $1.56(0.84-2.88)$ & $1.05(0.56-1.98)$ \\
\hline BMI 25-< 30 & 123 & 33 (26.8\%) & 1653 & 20.0 & I.II (0.65-I.9I) & $0.90(0.52-1.57)$ \\
\hline BMI $30-<35$ & 88 & $22(25.0 \%)$ & 1224 & 18.0 & 1 & 1 \\
\hline $\mathrm{BMI} \geq 35$ & 69 & $28(40.6 \%)$ & 906 & 30.9 & $1.73(0.99-3.03)$ & $1.89(1.08-3.32)$ \\
\hline
\end{tabular}

Notes: adjusted for age, sex, education, living together with a partner, physical activity, hypertension, smoking, history of myocardial infarction or stroke, cancer not in full remission, study center.

Abbreviations: $\mathrm{HR}$, hazard ratio; $\mathrm{Cl}$, confidence interval; CVD, cardiovascular disease.

diabetes, measures of abdominal obesity showed stronger associations with mortality than BMI. ${ }^{36}$ However, when WC categories were used instead of BMI categories, hazard ratios only slightly deviated from the null in the main analysis and in the sensitivity analyses $1-5$ (reference: $\mathrm{WC}<94 \mathrm{~cm}$ (males), $<80 \mathrm{~cm}$ (females)). Only after 
Table 3 Hazard Ratios of All-Cause Mortality by BMI Category in Persons with Diabetes at TI: The Heinz Nixdorf Recall Study

\begin{tabular}{|c|c|c|c|c|c|c|}
\hline & $\mathbf{N}$ & Deaths & Person Years & $\begin{array}{l}\text { Mortality Rate } \\
\text { (per } 1000 \text { py) }\end{array}$ & HR Crude $(95 \% \mathrm{Cl})$ & HR Adjusted (95\% Cl) \\
\hline \multicolumn{7}{|c|}{ All (N=777): BMI taken from $\mathrm{TI}$} \\
\hline BMI $18.5-<25$ & 101 & $27(26.7 \%)$ & 963 & 28.0 & $1.62(1.00-2.62)$ & $1.92^{\mathrm{b}}(1.17-3.14)$ \\
\hline BMI $25-<30$ & 298 & $64(21.5 \%)$ & 2964 & 21.6 & $1.24(0.85-1.83)$ & $1.14^{\mathrm{b}}(0.77-1.68)$ \\
\hline BMI $30-<35$ & 243 & $43(17.7 \%)$ & 2476 & 17.4 & 1 & 1 \\
\hline $\mathrm{BMI} \geq 35$ & 135 & $42(31.1 \%)$ & 1273 & 33.0 & $1.90(1.24-2.90)$ & $1.65^{\mathrm{b}}(1.07-2.55)$ \\
\hline \multicolumn{7}{|c|}{ All (N=777): BMI taken from T0 } \\
\hline BMI $18.5-<25$ & 92 & $20(21.7 \%)$ & 922 & 21.7 & $1.37(0.80-2.33)$ & $1.65^{\mathrm{b}}(0.96-2.84)$ \\
\hline BMI $25-<30$ & 315 & $75(23.8 \%)$ & 3051 & 24.6 & $1.55(1.06-2.27)$ & $1.43^{\mathrm{b}}(0.97-2.1 \mathrm{I})$ \\
\hline BMI $30-<35$ & 250 & $4 \mathrm{I}(16.4 \%)$ & 2581 & 15.9 & 1 & 1 \\
\hline $\mathrm{BMI} \geq 35$ & 120 & $40(33.3 \%)$ & 1122 & 35.6 & $2.24(1.45-3.46)$ & $2.10^{\mathrm{b}}(1.35-3.28)$ \\
\hline \multicolumn{7}{|c|}{$\begin{array}{l}\text { BMI taken from TO Exclusion of diagnosis of diabetes before the age of } 30 \text {, adjustment for diabetes duration, no adjustment for } \\
\text { hypertension, exclusion of death cases during the first two years of follow-up, exclusion of persons with history of stroke or } \\
\text { myocardial infarction/with cancer under treatment }(\mathrm{N}=646)\end{array}$} \\
\hline BMI $18.5-<25$ & 76 & 12 (I5.8\%) & 793 & I5.I & $1.30(0.66-2.57)$ & I.4I (0.70-2.84) \\
\hline BMI $25-<30$ & 251 & $42(16.7 \%)$ & 2593 & 16.2 & $1.40(0.86-2.27)$ & $1.29(0.79-2.11)$ \\
\hline BMI $30-<35$ & 218 & 27 (I2.4\%) & 2315 & 11.7 & 1 & 1 \\
\hline $\mathrm{BMI} \geq 35$ & 101 & $28(27.7 \%)$ & 1002 & 27.9 & $2.43(1.43-4.13)$ & $2.39(1.39-4.12)$ \\
\hline
\end{tabular}

Notes: ${ }^{a}$ In the analyses presented in this table the second visit to the study center (TI, between 2005 and 2008) was chosen as baseline. In one analysis, BMI measured at TI was used, in the other BMI measured five years earlier (at T0, between 2000 and 2003) was used. ${ }^{b}$ Adjusted for age, sex, education, living together with a partner, physical activity, hypertension, smoking, history of myocardial infarction or stroke, cancer not in full remission.

Abbreviations: $\mathrm{HR}$, hazard ratio; $\mathrm{Cl}$, confidence interval.

exclusion of never smokers, there was an indication that hazard ratios became higher with increasing WC. However, due to the small number of never smokers, confidence intervals were wide, and further studies with a larger sample of never smokers are warranted.

Other authors recommend measurement of body composition: Murphy et al also found that in patients with type 2 diabetes, mortality risk was largest in normal weight $(\mathrm{HR}=1.72$ (1.12 to 2.64) for comparison of BMI 18.4-24.9 versus 25.0-29.9), but this effect was strongly attenuated when the authors included thigh muscle size into the model $(\mathrm{HR}=1.36$ (0.87 to 2.11$)){ }^{37}$ Thus, if individuals with high BMI have not only elevated fat mass, but also elevated lean mass, the latter may explain the reduction in mortality; high $\mathrm{BMI}$ is less protective when muscle mass is low. ${ }^{22,37}$ However, adding estimated FFM as a potential mediator to our regression models led to only slight changes of HRs.

For analyses of associations between adiposity and death in the general population, Pischon et al suggested that measures of both general and abdominal adiposity should be included. ${ }^{38}$ When WC was additionally adjusted for in the main analysis, the hazard ratio was still lowest for BMI 25.0-29.9. Therefore, the obesity paradox was not due to lack of adjustment for measures of abdominal obesity in our study.

\section{Treatment Bias}

Several authors assumed that lower mortality in obesity may result from a better treatment of obese persons with diabetes. ${ }^{24}$ However, our data did not provide evidence that overweight or obese persons are given privileged medical care. In our pooled cohort, diabetes was not diagnosed earlier in the obese, the proportion of unknown diabetes was about the same in obese and non-obese, and, moreover, the proportion of persons receiving diabetes therapy was similar in obese and non-obese. In addition, at baseline, persons with $\mathrm{BMI} \geq 30.0 \mathrm{~kg} / \mathrm{m}^{2}$ exhibited higher HbAlc values, less favourable levels of lipids and higher values of blood pressure than persons with BMI $<30.0 \mathrm{~kg} / \mathrm{m}^{2}$.

\section{Collider Bias}

Lajous et al found an obesity paradox in women with diabetes, but not in women without diabetes, and they concluded that the paradox in persons with diabetes can be "explained away" by the collider bias. ${ }^{16}$ In our study, 
Table 4 Distribution of Risk Factors for Type 2 Diabetes by BMI Category Separately for the Whole Study Group and for Persons with Type 2 Diabetes: The Heinz Nixdorf Recall Study

\begin{tabular}{|c|c|c|c|c|c|c|}
\hline & \multicolumn{3}{|c|}{ Whole Study Group } & \multicolumn{3}{|c|}{ Persons with Type 2 Diabetes } \\
\hline & BMI $<27.5$ & BMI $\geq 27.5$ (Ref) & PR (95\% Cl) & BMI $<27.5$ & BMI $\geq 27.5$ (Ref) & PR $(95 \% \mathrm{Cl})$ \\
\hline$N$ & 2459 & 2326 & & 214 & 502 & \\
\hline Educational years $\leq 13$ & $157 \mid(64.0 \%)$ & $1631(70.4 \%)$ & $0.90^{\mathrm{a}, \mathrm{e}}(0.87-0.94)$ & 144 (67.3\%) & $340(67.7 \%)$ & $0.99^{\mathrm{a}}(0.89-1.10)$ \\
\hline Educational years $>13$ (ref) & $885(36.0 \%)$ & $687(29.6 \%)$ & & $70(32.7 \%)$ & $162(32.3 \%)$ & \\
\hline Smoking (yes) & $672(27.3 \%)$ & 449 (19.4\%) & $1.35^{\mathrm{b}}(1.22-1.50)$ & $6 \mathrm{I}(28.5 \%)$ & 95 (18.9\%) & $1.52^{\mathrm{b}}(1.16-1.99)$ \\
\hline Smoking (no) (ref) & $1787(72.7 \%)$ & $1872(80.7 \%)$ & & I53 (7I.5\%) & 407 (81.1\%) & \\
\hline Hypertension (yes) & $1109(45.1 \%)$ & $1564(67.4 \%)$ & $0.72^{\mathrm{b}}(0.69-0.76)$ & $143(66.8 \%)$ & 419 (83.5\%) & $0.80^{\mathrm{b}}(0.73-0.89)$ \\
\hline Hypertension (no) (ref) & I 347 (54.9\%) & 755 (32.6\%) & & 71 (33.2\%) & $83(16.5 \%)$ & \\
\hline Male sex & II $48(46.7 \%)$ & $1233(53.0 \%)$ & $0.88^{\mathrm{c}}(0.83-0.93)$ & 134 (62.6\%) & $323(64.3 \%)$ & $0.97^{c}(0.86-1.10)$ \\
\hline \multirow[t]{2}{*}{ Female sex (ref) } & $|3| \mid(53.3 \%)$ & 1093 (47.0\%) & & $80(37.4 \%)$ & $179(35.7 \%)$ & \\
\hline & BMI $<27.5$ & BMI $\geq 27.5$ (ref) & B (95\% Cl) & BMI $<27.5$ & BMI $\geq 27.5$ (ref) & B (95\% Cl) \\
\hline Age (years), & $58.7 \pm 7.8$ & $60.6 \pm 7.7$ & $-1.91^{c}(-2.35 ;-1.47)$ & $62.0 \pm 8.0$ & $62.2 \pm 7.4$ & $-0.23^{c}(-1.44 ; 0.98)$ \\
\hline Risk alleles $^{d}$ & $79.0 \pm 5.4$ & $78.7 \pm 5.3$ & $0.26^{\mathrm{c}}(-0.08 ; 0.60)$ & $80.6 \pm 5.4$ & $79.6 \pm 5.3$ & $1.04^{\mathrm{c}}(0.09 ; 2.00)$ \\
\hline
\end{tabular}

Notes: ${ }^{2}$ Adjusted for age and sex; ${ }^{b}$ Adjusted for age, sex, and education; ${ }^{c} \mathrm{No}$ further adjustment; ${ }^{\mathrm{d}} \mathrm{N}=4785$ for the whole group, and 716 persons with diabetes (cf. methods

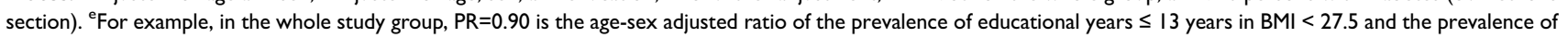
educational years $\leq 13$ years in $\mathrm{BMI} \geq 27.5$.

Abbreviations: PR, prevalence ratio; $\mathrm{Cl}$, confidence interval; $B$, regression coefficient of the linear regression model.

restricting the analyses to persons with diabetes may cause a collider bias because non-obese persons who developed diabetes are likely to exhibit more often risk factors for diabetes other than obesity. Thus, in a population of persons with diabetes, non-obese persons are more likely to smoke, and to have more risk alleles for diabetes than obese persons, and, thus, may have an increased mortality risk. Such an inverse association is an artefact and occurs only upon conditioning on diabetes but not in the whole population.

In our study, collider bias was present. For the whole population, we calculated prevalence ratios for low education, smoking, and hypertension comparing BMI $<27.5$ to $\mathrm{BMI} \geq 27.5$. According to the idea of the collider bias, these prevalence ratios were slightly larger when calculated for the subgroup with diabetes. Eg, in persons with diabetes, the prevalence of smoking was 1.52 times larger in $\mathrm{BMI}<27.5$ than in BMI $\geq 27.5$, but in the whole population, the prevalence of smoking was only 1.35 times larger in BMI $<27.5$ than in BMI $\geq 27.5$. However, this does not mean that the lack of an increased mortality in the obese is due to the collider bias: the excess prevalence of these risk factors in the non-obese persons with diabetes was small, and, moreover, except for diabetes risk alleles, we adjusted for all these risk factors other than obesity in our multivariable models. Among persons with diabetes, the mean number of diabetes risk alleles was 80.6 for $\mathrm{BMI}<27.5$, and 79.6 for $\mathrm{BMI} \geq 27.5$.
This tiny difference is unlikely to cause the lack of excess mortality in persons with larger BMI.

\section{Comparison with Other Studies}

In few other studies with diabetes populations, careful sensitivity analyses had also been carried out. Tobias et al found a U-shaped association between BMI and mortality with an optimum in normal BMI. ${ }^{20}$ After exclusion of ever smokers, the shape of the curve and the position of the nadir remained unchanged, but hazard ratios for overweight and obese persons were slightly larger. Dhalwani et al reported a strong obesity paradox in persons with diabetes, and results were almost the same after excluding persons with cardiovascular or cancer disease at baseline, and after excluding persons who died within the first two years after baseline. ${ }^{8}$

\section{Limitations and Strengths}

Our study has several limitations. First, the oral glucose tolerance test was not done in the two cohort studies, and thus, some persons with diabetes might have been missed in our analyses. Second, we only addressed all-cause mortality but not cardiovascular or cancer mortality. Third, the number of never smokers was small so that our estimates of mortality in never smokers with diabetes were rather imprecise. Fourth, we did not have data on BMI in earlier lifetime so that we could not compare persons with lateonset obesity to persons with early-onset obesity. Fifth, 
body composition was not measured, and we used waist circumference as a marker of abdominal obesity.

Strengths of our study are the use of data from two population-based cohort studies with well characterized subjects, and with long follow-up times up to 18 years. Moreover, in our sensitivity analyses, we took into account several points of view rarely addressed in other studies: we used not only BMI, but also WC as anthropometric measure; we also used BMI values measured several years prior to baseline; we assessed the presence of treatment bias and of collider bias.

\section{Conclusion}

Obesity is a strong risk factor for diabetes, and, thus, it is striking that moderate obesity reduces the mortality risk in people with diabetes. This brings up the idea that artefacts might be involved when mortality is found to be lowest for overweight or obesity. In our middle-aged to older study population with diabetes, the risk of all-cause mortality was lowest in moderate obesity. Our results remained stable when sensitivity analyses to remove several biases were done. Moreover, the obesity paradox could not be explained by treatment bias or collider bias. Nevertheless, residual confounding of smoking might contribute to the obesity paradox. Our analyses gave an indication that mortality risk is increased in never smokers with $\mathrm{BMI} \geq 35$. Therefore, larger cohorts of never smokers are desirable. Moreover, studies with anthropometric measures other than BMI or WC might lead to different results, and there is still a lack of cohort studies with measurement of body composition.

\section{Abbreviations}

ATC Code, Anatomical Therapeutic Chemical Code; BMI, Body mass index; CI, Confidence interval; CVD, Cardiovascular disease; FFM, Fat-free mass; HNR Study, Heinz Nixdorf Recall Study; HR, Hazard ratio; ISCED, International Standard Classification of Education; PR, Prevalence ratio; SD, Standard deviation; SHIP, Study of Health in Pomerania; WC, Waist circumference.

\section{Acknowledgments}

The authors express their gratitude to all study participants of the Heinz Nixdorf Recall (HNR) Study, the personnel of the HNR study center and the EBT-scanner facilities, the investigative group and all former employees of the HNR study. The authors also thank the Advisory Board of the HNR Study: T. Meinertz, Hamburg, Germany (Chair); C. Bode, Freiburg, Germany; P.J. de Feyter, Rotterdam, Netherlands; B. Güntert,
Hall i.T., Austria; F. Gutzwiller, Bern, Switzerland; H. Heinen, Bonn, Germany; O. Hess $(\dagger)$, Bern, Switzerland; B. Klein $(\dagger)$, Essen, Germany; H. Löwel, Neuherberg, Germany; M. Reiser, Munich, Germany; G. Schmidt (†), Essen, Germany; M. Schwaiger, Munich, Germany; C. Steinmüller, Bonn, Germany; T. Theorell, Stockholm, Sweden; and S.N Willich, Berlin, Germany.

\section{Funding}

The authors thank the Heinz Nixdorf Foundation [Chairman: Martin Nixdorf; Past Chairman: Dr jur. Gerhard Schmidt $(\dagger)]$, for their generous support of this study. Parts of the study were also supported by the German Research Council (DFG) [DFG project: EI 969/2-3, ER 155/6-1;6-2, HO 3314/ 2-1;2-2;2-3;4-3, INST 58219/32-1, JO 170/8-1, KN 885/3-1, PE 2309/2-1, SI 236/8-1;9-1;10-1,], the German Ministry of Education and Science [BMBF project: 01EG0401, 01GI0856, 01GI0860, 01GS0820_WB2-C, 01ER1001D, 01GI0205], the Ministry of Innovation, Science, Research and Technology, North Rhine-Westphalia (MIWFT-NRW), the Else Kröner-Fresenius-Stiftung [project: 2015_A119] and the German Social Accident Insurance [DGUV project: FF-FP295]. Furthermore the study was supported by the Competence Network for HIV/AIDS, the deanship of the University Hospital and IFORES of the University DuisburgEssen, the European Union, the German Competence Network Heart Failure, Kulturstiftung Essen, the Protein Research Unit within Europe (PURE), the Dr. WernerJackstädt Stiftung and the following companies: Celgene $\mathrm{GmbH}$ München, Imatron/GE-Imatron, Janssen, Merck KG, Philips, ResMed Foundation, Roche Diagnostics, Sarstedt AG\&Co, Siemens HealthCare Diagnostics, Volkswagen Foundation.

\section{Disclosure}

There are no competing interests to declare.

\section{References}

1. Flegal KM, Kit BK, Orpana H, Graubard BI. Association of all-cause mortality with overweight and obesity using standard body mass index categories: a systematic review and meta-analysis. JAMA. 2013;309 (1):71-82. doi:10.1001/jama.2012.113905

2. Di Angelantonio E, Bhupathiraju SN, Wormser D; The Global BMI Mortality Collaboration. Body-mass index and all-cause mortality: individual-participant-data meta-analysis of 239 prospective studies in four continents. Lancet. 2016;388(10046):776-786. doi:10.1016/ S0140-6736(16)30175-1

3. Adams KF, Schatzkin A, Harris TB, et al. Overweight, obesity, and mortality in a large prospective cohort of persons 50 to 71 years old. $N$ Engl J Med. 2006;355(8):763-778. doi:10.1056/NEJMoa055643 
4. Han SJ, Boyko EJ. The evidence for an obesity paradox in type 2 diabetes mellitus. Diabetes Metab J. 2018;42(3):179-187. doi:10.4093/dmj.2018.0055

5. Zaccardi F, Dhalwani NN, Papamargaritis D, et al. Nonlinear association of BMI with all-cause and cardiovascular mortality in type 2 diabetes mellitus: a systematic review and meta-analysis of 414,587 participants in prospective studies. Diabetologia. 2017;60 (2):240-248. doi:10.1007/s00125-016-4162-6

6. Chang HW, Li YH, Hsieh CH, Liu PY, Lin GM. Association of body mass index with all-cause mortality in patients with diabetes: a systematic review and meta-analysis. Cardiovasc Diagn Ther 2016;6:109-119. doi:10.21037/cdt.2015.12.06

7. Kwon Y, Kim HJ, Park S, Park YG, Cho KH. Body mass index-related mortality in patients with type 2 diabetes and heterogeneity in obesity paradox studies: a dose-response meta-analysis. PLoS One. 2017;12(1):e0168247. doi:10.1371/journal.pone.0168247

8. Dhalwani NN, Zaccardi F, Davies MJ, Khunti K. Body mass index and mortality in people with and without diabetes: a UK Biobank study. Nutr Metab Cardiovasc Dis. 2018;28(12):1208-1216. doi:10.1016/j.numecd.2018.07.007

9. Lee EY, Lee YH, Yi SW, Shin SA, Yi JJ. BMI and all-cause mortality in normoglycemia, impaired fasting glucose, newly diagnosed diabetes, and prevalent diabetes: a cohort study. Diabetes Care. 2017;40:1026-1033. doi:10.2337/dc16-1458

10. Mulnier HE, Seaman HE, Raleigh VS, Soedamah-Muthu SS, Colhoun HM, Lawrenson RA. Mortality in people with type 2 diabetes in the UK. Diabet Med. 2006;23(5):516-521. doi:10.1111/ j.1464-5491.2006.01838.x

11. Khalangot M, Tronko M, Kravchenko V, Kulchinska J, Hu G. Body mass index and the risk of total and cardiovascular mortality among patients with type 2 diabetes: a large prospective study in Ukraine. Heart. 2009;95(6):454-460. doi:10.1136/hrt.2008.150524

12. Lyerly GW, Sui X, Lavie CJ, Church TS, Hand GA, Blair SN. The association between cardiorespiratory fitness and risk of all-cause mortality among women with impaired fasting glucose or undiagnosed diabetes mellitus. Mayo Clin Proc. 2009;84(9):780-786. doi: 10.4065/84.9.780

13. Logue J, Walker JJ, Leese G, et al. Association between BMI measured within a year after diagnosis of type 2 diabetes and mortality. Diabetes Care. 2013;36(4):887-893. doi:10.2337/dc12-0944

14. Zhao W, Katzmarzyk PT, Horswell R, et al. Body mass index and the risk of all-cause mortality among patients with type 2 diabetes. Circulation. 2014;130:2143-2151. doi:10.1161/CIRCULATIONAHA. 114.009098

15. Costanzo P, Cleland JG, Pellicori P, et al. The obesity paradox in type 2 diabetes mellitus: relationship of body mass index to prognosis: a cohort study. Ann Intern Med. 2015;162:610-618. doi:10.7326/ M14-1551

16. Lajous M, Bijon A, Fagherazzi G, et al. Body mass index, diabetes and mortality in French women: explaining away a "paradox". Epidemiology. 2014;25:10-14. doi:10.1097/EDE.0000000000000031

17. Jackson CL, Yeh HC, Szklo M, et al. Body mass index and all-cause mortality in US adults with and without diabetes. J Gen Intern Med. 2013;29:25-33. doi:10.1007/s11606-013-2553-7

18. Thomas G, Khunti K, Curcin V, et al. Obesity paradox in people newly diagnosed with type 2 diabetes with and without prior cardiovascular disease. Diabetes Obes Metab. 2014;16:317-325. doi:10.1111/dom. 12217

19. Eeg-Olofsson K, Cederholm J, Nilsson PM, et al. Risk of cardiovascular disease and mortality in overweight and obese patients with type 2 diabetes: an observational study in 13,087 patients. Diabetologia. 2009;52:65-73. doi:10.1007/s00125-008-1190-x

20. Tobias DK, Pan A, Jackson CL, et al. Body-mass index and mortality among adults with incident type 2 diabetes. $N$ Engl $\mathrm{J} \mathrm{Med}$. 2014;370:233-244. doi:10.1056/NEJMoa1304501
21. Tobias DK, Manson JE. The obesity paradox in type 2 diabetes and mortality. Am J Lifestyle Med. 2016;12:244-251. doi:10.1177/ 1559827616650415

22. Prado CM, Gonzalez MC, Heymsfield SB. Body composition phenotypes and obesity paradox. Curr Opin Clin Nutr Metab Care. 2015;18(6):535-551. doi:10.1097/MCO.0000000000000216

23. Rothman KJ. BMI-related errors in the measurement of obesity. Int J Obes. 2008;32(S3):S56-S59. doi:10.1038/ijo.2008.87

24. Standl E, Erbach M, Schnell O. Defending the con side: obesity paradox does not exist. Diabetes Care. 2013;36(suppl 2):S282S286. doi:10.2337/dcS13-2040

25. Preston SH, Stokes A. Obesity paradox: conditioning on disease enhances biases in estimating the mortality risks of obesity. Epidemiology. 2014;25(3):454-461. doi:10.1097/EDE.0000000000 000075

26. Schmermund A, Möhlenkamp S, Stang A, et al. Assessment of clinically silent atherosclerotic disease and established and novel risk factors for predicting myocardial infarction and cardiac death in healthy middle-aged subjects: rationale and design of the Heinz Nixdorf RECALL Study. Risk factors, evaluation of coronary calcium and lifestyle. Am Heart J. 2002;144:212-218. doi:10.1067/ mhj.2002.123579

27. John U, Greiner B, Hensel E, et al. Study of Health in Pomerania (SHIP): a health examination survey in an east German region: objectives and design. Soz Praventivmed. 2001;46:186-194. doi:10.1007/BF01324255

28. Völzke H, Alte D, Schmidt CO, et al. Cohort profile: the Study of Health in Pomerania. Int J Epidemiol. 2011;40:294-307. doi:10.1093/ ije/dyp394

29. Kowall B, Lehnich AT, Erbel R, Moebus S, Jöckel KH, Stang A. Associations between sleep characteristics and weight gain in an older population: results of the Heinz Nixdorf Recall Study. Nutr Diabetes. 2016;6(8):e225. doi:10.1038/nutd.2016.32

30. Ittermann $\mathrm{T}$, Werner $\mathrm{N}$, Lieb $\mathrm{W}$, et al. Changes in fat mass and fat-free mass are associated with incident hypertension in four population-based studies from Germany. Int $J$ Cardiol. 2019;274:372-377. doi:10.1016/j.ijcard.2018.09.035

31. Kuch B, Gneiting B, Döring M, et al. Indexation of left ventricular mass in adults with a novel approximation for fat-free mass. J Hypertens. 2001;19:135-142. doi:10.1097/00004872-20010100000018

32. Markus MRP, Werner N, Schipf S, et al. Changes in body weight and composition are associated with changes in left ventricular geometry and function in the general population: SHIP (Study of Health in Pomerania). Circ Cardiovasc Imaging. 2017;10:e005544. doi:10.1161/CIRCIMAGING.116.005544

33. Leitzmann MF, Moore SC, Koster A, et al. Waist circumference as compared with body-mass index in predicting mortality from specific causes. PLoS One. 2011;6(4):e18582. doi:10.1371/journal.pone. 0018582

34. World Health Organisation. Obesity: Preventing and Managing the Global Epidemic; 2000:44-46

35. Jenkins DA, Bowden J, Robinson HA, et al. Adiposity-mortality relationships in type 2 diabetes, coronary heart disease, and cancer subgroups in the UK Biobank, and their modification by smoking. Diabetes Care. 2018;41:1878-1886. doi:10.2337/dc17-2508

36. Sluik D, Boeing H, Montonen J, et al. Associations between general and abdominal adiposity and mortality in individuals with diabetes mellitus. Am J Epidemiol. 2011;174:22-34. doi:10.1093/aje/kwr048

37. Murphy RA, Reinders I, Garcia ME, et al. Adipose tissue, muscle, and function: potential mediators of associations between body weight and mortality in older adults with type 2 diabetes. Diabetes Care. 2014;37(12):3213-3219. doi:10.2337/dc14-0293

38. Pischon T, Boeing H, Hoffmann K, et al. General and abdominal obesity and risk of death in Europe. $N$ Engl J Med. 2008;359:2105-2120. doi:10.1056/NEJMoa0801891 


\section{Publish your work in this journal}

Diabetes, Metabolic Syndrome and Obesity: Targets and Therapy is an international, peer-reviewed open-access journal committed to the rapid publication of the latest laboratory and clinical findings in the fields of diabetes, metabolic syndrome and obesity research. Original research, review, case reports, hypothesis formation, expert opinion and commentaries are all considered for publication. The manuscript management system is completely online and includes a very quick and fair peer-review system, which is all easy to use. Visit http://www.dovepress.com/testimonials.php to read real quotes from published authors.

Submit your manuscript here: https://www.dovepress.com/diabetes-metabolic-syndrome-and-obesity-targets-and-therapy-journal 